\title{
Considerações sobre vida e trabalho de mulheres internadas em uma unidade psiquiátrica
}

\author{
THE LIFE AND WORK OF WOMEN HOSPITALIZED AT A PSYCHIATRIC UNIT \\ CONSIDERACIONES SOBRE VIDA Y TRABAJO DE MUJERES INTERNADAS EN UNA UNIDAD PSIQUIÁTRICA
}

Jacileide Guimarães ${ }^{1}$, Soraya Maria de Medeiros ${ }^{2}$

\begin{abstract}
RESUMO
Estudo realizado no setor feminino de uma clínica psiquiátrica na cidade de Mossoró-RN. Nosso objetivo foi investigarmos as ocorrências psiquiátricas, articuladas às formas de vida e de trabalho dos sujeitos entrevistados-perfil epidemiológico da clínica. Aplicamos entrevistas semiestruturadas a $10 \%$ do número de mulheres internadas, paralelamente, consultamos os prontuários médicos e abordamos a equipe de enfermagem a respeito das pacientes entrevistadas. O material coletado enfatizou um elevado grau de insatisfação das mulheres internadas, tanto no âmbito privado quanto na esfera laboral de suas vidas. Após a primeira internação, essas mulheres ingressaram na "carreira psiquiátrica", impulsionada pela assistência psiquiátrica tradicional.
\end{abstract}

\section{PALAVRAS-CHAVE}

Mulheres. Processo saúde-

doença. Enfermagem

psiquiátrica. Assistência.

\section{ABSTRACT}

This study was carried out at the women's sector of a psychiatric hospital in the city of Mossoró, RN, Brazil. Our aim was to learn about the life and work aspects regarding first hospitalizations and rehospitalizations of theses women. To this end the authors applied semistructured interviews with $10 \%$ of the hospitalized women, studied their medical files and talked to the hospital's nursing staff about the women that were interviewed. The material collected showed a high level of dissatisfaction with regards to their private and professional lives. After their first hospitalization, as a result of the traditional psychiatric care, these women initiated they "psychiatric trajectory".
\end{abstract}

\section{KEYWORDS}

Women. Health-diseases process. Psychiatric nursing. Assistance

\begin{abstract}
RESUMEN
Estudio realizado en el sector femenino de una clínica psiquiátrica de la ciudad de Mossoró-RN. Nuestro objetivo fue investigar las ocurrencias psiquiátricas, articuladas a las formas de vida y de trabajo de los sujetos entrevistadosperfil epidemiológico de la clínica. Aplicamos entrevistas semi-estructuradas a $10 \% \mathrm{del}$ número de mujeres internadas. Paralelamente consultamos las histórias clínicas y abordamos al equipo de enfermería respecto a las pacientes entrevistadas. El material recolectado enfatizó un elevado grado de insatisfacción de las mujeres internadas, tanto en el ámbito privado cuanto en la esfera laboral de sus vidas. Después del primer internamiento, esas mujeres ingresaron a la "carrera psiquiátrica", impulsadas por la asistencia psiquiátrica tradicional.
\end{abstract}

\section{PALABRAS-CLAVE}

Mujeres. Proceso saludenfermedad. Enfermeria psiquiátrica. Asistencia.

\author{
1 Doutoranda do \\ Programa de Pós- \\ Graduação da Escola de \\ Enfermagem de \\ Ribeirão Preto da \\ Universidade de São \\ Paulo - EERP/USP \\ jaciguim@yahoo.com.br \\ 2 Professora Doutora da \\ Universidade Federal do \\ Rio Grande do Norte- \\ UFRN, Departamento \\ de Enfermagem.
}




\section{INTRODUÇÃO}

Abordar o processo de vida e trabalho versus saúde-doença e seu impacto na saúde mental, remete à discussão subjacente que constitui-se como pano de fundo e suporte teórico da questão: a causalidade do processo saúde-doença. Segundo Barata (1) a compreensão do processo de determinação da doença é central na área de conhecimento denominada como epidemiologia, que nos interessa, por constituir o mapa que reflete as ocorrências registradas das doenças, considerando-se a interpretação de tempo e lugar de inserção.

Enquanto conceito, a causalidade é determinada, de um lado, pelas condições concretas de existência, de outro, pela capacidade intelectiva do homem em cada contexto histórico, vale dizer, enquanto conceito, categoria explicativa, a questão da causa é revestida de historicidade ${ }^{(1)}$.

Há necessidade, portanto, no dizer dessa autora, de se reconstruir a história do conceito, na perspectiva de apreendermos as transformações de conteúdo pelas quais o mesmo passou.

Sendo os conceitos construções históricas, constituem processos que são uma produção de sujeitos sociais, resultante de relações socio-políticas e culturais em determinado tempo e determinada organização social. Dessa forma, nesse estudo, alertamos para o processo saúde-doença no que tange à saúde mental, relacionado às formas de produção e reprodução da sociedade que, por sua vez, imprimem conceitos e relações entre saúde e doença mental, especificamente.

Para Queiroz; Salum ${ }^{(2)}$ a sociedade ao produzir-se, estabelece formas específicas de trabalhar, onde essas formas de trabalho vão produzir um determinado potencial de benefícios assim como um determinado potencial de riscos à saúde. Esses potenciais de benefícios e riscos são determinados pelas formas específicas de viver e de trabalhar em sociedade, que competem para o impacto da determinação social do processo saúde-doença e, acrescentamos, por extensão/reciprocidade, também no âmbito da saúde mental.

Assim tem-se duas grandes vertentes de investigação: as formas de viver e as formas de trabalhar. São duas vertentes que se completam, se articulam e potencializam-se, no sentido de produzirem benefícios e/ou riscos à saúde/saúde mental, assim como aparentes benefícios em determinados momentos e posteriores malefícios ou vice-versa.

Considerando as formas de trabalhar, pode-se mencionar os processos de trabalho que promovem o desgaste do corpo e da mente dos trabalhadores, a exposição a riscos e agravos à saúde e os acidentes com conseqüências fatais ou que deixam seqüelas.

O desgaste do corpo durante o processo produtivo gera patologias específicas para cada tipo de atividade ocupacional, além das diferentes modalidades de acidentes de trabalho, essas características encontram-se também diretamente relacionadas com o tipo de trabalho executado. (...) Além do desgaste mecânico provocado pela repetição contínua e prolongada aos movimentos corporais durante oito ou mais horas seguidas diárias, temos ainda o processo de degeneração orgânica associado às demais doenças ocupacionais, decorrentes do contato com substâncias tóxicas das mais variadas espécies ${ }^{(3)}$.

Considerando o processo saúde-doença mental, há que se ressaltar que muitas vezes não se faz a associação do "nexo causal" entre o trabalho e a incidência/desenvolvimento do processo de sofrimento psíquico. Citamos ainda Possas ${ }^{(3)}$, para efeito de ilustração/aproximação acerca da problemática do nexo causal, apreendido mais facilmente quando se trata de acidentes ou manifestações visíveis e imediatamente mensuráveis.

Uma parte considerável dos locais de trabalho está permanentemente envolta por poeiras, névoas e fatores de substâncias, muitas das quais altamente tóxicos. Além das dificuldades legais para sua comprovação e do sub registro de suas conseqüências sobre a saúde nas estatísticas oficiais, a maioria dos trabaIhadores ignora como essas substâncias afetam o seu organismo, não tendo portanto, consciência dos riscos de saúde e da vida que estão implícitos nas diferentes modalidades de tarefas em que estão envolvidos. A inviabilidade de boa parte das substâncias e poeiras tóxicas, bem como o caráter cumulativo dos efeitos, que muitas vezes só trarão conseqüências para o organismo após alguns anos de trabalho, dificulta a percepção do nexo causal entre o trabalho e a doença, muito mais claro no caso do acidente do trabalho dado o seu caráter súbito e traumático ${ }^{(3)}$.
Rev Esc Enferm USP 2003; 37(2): 51-8. 
Como exemplo similar ao acidente de trabalho, porém não tão óbvio a curto prazo, como adverte a autora, trazemos os casos de Karoshi (de Karo: trabalho estafante; e Shi: morte) no Japão, onde já houve, segundo Joffily ${ }^{(4)}$ mais de 1.500 casos de morte súbita por estafa, resultantes do ritmo de trabalho no mundo atual dentro da chamada Terceira Revolução Industrial - o Toyotismo - denominado de "by stress" (sob tensão).

Porém, o modelo de produção, ordenado pela Terceira Revolução Industrial, tem muitas outras implicações e causa outros impactos na saúde do trabalhador, particularmente na sua saúde mental que, embora esteja constituindo-se como parte do projeto de estudos de teóricos na atualidade, ainda carece de estudos mais aprofundados sobre suas conseqüências para a saúde mental no cotidiano desses trabalhadores.

Seria talvez essa "névoa tóxica" de que fala Possas ${ }^{(3)}$, usada aqui com sentido figurado, para trazer à luz a questão do processo de trabalho no mundo globalizado e sua repercussão no processo de saúde-doença mental dos trabalhadores.

\begin{abstract}
A chamada globalização na economia e suas implicações sociais, políticas e culturais emerge como uma questão central constituindo-se em um dos grandes desafios da sociedade contemporânea. A penetração e as ressonâncias da globalização permeiam o modelo econômico, a estrutura da sociedade, as relações sociais de produção, as relações interpessoais, as subjetividades e a produção da vida cotidiana. É flagrante o sentimento de insegurança e intranqüilidade advindos da convivência no cotidiano com as transformações econômicas resultantes do processo de globalização da economia ${ }^{(5)}$.
\end{abstract}

Para Medeiros ${ }^{(5)}$, a globalização é o resultado da multiplicação cumulativa das relações estabelecidas entre os agentes econômicos advindos de diferentes pontos do espaço mundial, tendo como condição fundamental para seu avanço a abertura dos mercados nacionais, a supressão das fronteiras que separam os países e localidades e a competição como força propulsora.

A concepção político-ideológica que respalda esse processo é o neoliberalismo. $\mathrm{O}$ ideário neoliberal se embasa na desigualdade como valor fundamental para estimular a vitalidade da concorrência, onde esta desigualdade é tida como implementadora da prosperidade dos sujeitos sociais.

A lógica neoliberal abole a democracia como valor central, considerando que a democracia enquanto expressão da vontade da maioria é incompatível com a liberdade individual dos agentes econômicos. Assim como a Terceira Revolução Industrial, tem como doutrina o neoliberalismo, a globalização corresponde à sua expressão na escala de produção e reprodução na forma do capitalismo vigente.

Dentro desse contexto da Terceira Revolução Industrial, há que se lançar luzes sobre as possibilidades e limites do processo saúdedoença mental em suas determinações sociais, considerando-se as duas vertentes supracitadas neste estudo: as formas de viver e de trabalhar, geradoras de processos de benefícios e desgastes da saúde da população.

Temos no cenário do atual mundo do trabalho uma forte retração nos empregos e conseqüente aumento do desemprego, principalmente na indústria; formas de trabalho parcial, precário e informal; terceirização; tendências à estagnação no consumo dos bens produzidos, paralelo à reação dos trabalhadores de perplexidade, dessindicalização, fragmentação, competição acirrada e perda de conquistas trabalhistas anteriores ${ }^{(6)}$.

Deflagra-se a geração de estresse, estafa, insegurança, ansiedade, doenças psicossomáticas, violência, medo e agravamento das doenças crônico-degenerativas pela potencialização de quadros associados e/ou agravados por depressão do sistema nervoso central e do sistema imunológico, além dos temores advindos dos riscos de usos indevidos e anti-éticos das sofisticadas descobertas da engenharia genética e da informática.

No cenário do mundo privado das subjetividades e intersubjetividades têm-se a perda, substituição e/ou negligência de valores éticos e da sensibilidade humana pelo ritmo acelerado da produção, da comunicação de massa e da competição, gerando hostilidade, agressividade, radicalismos, preconceitos raciais, étnicos, sexuais e de gênero.

Recrudesce a violência contra as chamadas minorias políticas: a mulher, a criança, o idoso, os animais, enfim, os excluídos “de
Considerações sobre

vida e trabalho

de mulheres

internadas em uma

unidade psiquiátrica 
Jacileide Guimarães Soraya Maria de Medeiros todo o gênero" - para lembrar a terminologia "loucos de todo o gênero" muito em voga na literatura psiquiátrica científica e judiciária brasileira, até recentemente. Aflora o sentimento de desenraizamento, já conhecido e estudado como "experiência do vazio", por aqueles que migram dos seus "habitats" naturais e vão à procura de melhores condições de trabalho e de vida e encontram mais solidão, sentimento de baixa auto-estima, frustrações e revoltas, assim como, o sentimento de abandono e rejeição daqueles que não são absorvidos pelo mercado de trabalho ou que não têm mais lugar no novo modelo de família.

$\mathrm{Na}$ esteira da redefinição atual dos conceitos e práticas em saúde, Bastos; Castiel ${ }^{(7)}$ definem os campos da saúde mental e da epidemiologia como possíveis "labirintos" que à luz da ciência contemporânea se descobrem:

\section{(...) Tanto a Epidemiologia como o campo} da Saúde Mental tem pela frente desafios que pertencem a uma mesma problemática: perceber a complexa diversidade dos elementos que envolvem os fenômenos Saúde/Doença, inalcançável diante do reducionismo homoge-neizador do dispositivo epidemiológico e das atuais limitações das definições do Mental. Através de contribuições que aprofundem esta ordem de problemas será possível ampliar o entendimento do adoecer humano e propor modos mais satisfatórios de intervenção ${ }^{(7)}$

Consideramos que olhar para o doente - e não para a doença isoladamente -, em seu contexto de vida e trabalho, consiste em uma forma de aproximação mais vinculada a realidade socio-econômica e cultural das pessoas. Somando-se a isso a necessidade de se abordar o processo saúde-doença mental de forma transdisciplinar, ou seja, permeiado pelos diferentes saberes que compõem a possibilidade do todo na condição humana. Reiteramos a importância da renovação e articulação dos campos/labirintos do mental e da epidemiologia em prol de contribuições que superem as limitações dos reducionismos e das definições cristalizadas para alcançarmos, ou pelo menos, nos aproximarmos da realidade do processo saúde-doença, como de fato ele se apresenta: uma complexa diversidade.

\section{TRAJETÓRIA METODOLÓGICA}

Empreendemos o presente estudo com o objetivo de investigarmos as ocorrências psiquiátricas, articuladas às formas de vida e de trabalho dos sujeitos entrevistados - perfil epidemiológico - em uma clínica psiquiátrica de médio porte.

Conforme a comunicação por nós realizada e a autorização prévia por parte da direção da Casa de Saúde São Camilo de Léllis (CSSCL - Mossoró/RN), passamos a visitar a Unidade de Cuidados Intensivos (UCI) Feminino daquela instituição. Mantivemos um contato inicial com a enfermeira responsável e tomamos conhecimento da rotina desempenhada pelo pessoal de enfermagem nos setores interno e externo da unidade.

Posteriormente conferimos nos registros de internação a informação de uma média de 45 pacientes internadas por mês na Unidade, dividida nos setores interno e externo, correspondendo respectivamente, ao setor de manifestações agudas dos transtornos e, setor dos "estados controlados". Passamos a realizar visitas de campo nos turnos matutino e vespertino. Após esclarecermos os princípios de sigilo e anonimato quanto ao uso do material coletado nas entrevistas, assim como, a liberdade dos participantes de participar ou não ou ainda de desistência mesmo depois de iniciada a coleta, aplicamos uma entrevista semi-estruturada a $10 \%$ do total das mulheres internadas na unidade e em condições de comunicação (5 mulheres), visando apreender as suas histórias de vida temáticas. A questão norteadora pedia para que os sujeitos da pesquisa falassem sobre a sua vida e em que tinham trabalhado até o surgimento da primeira internação em hospital ou clínica psiquiátrica.

Conforme o esclarecimento/consentimento prévio, as entrevistas foram gravadas e transcritas em parte, no corpo desse trabalho, identificadas pela letra E de ENTREVISTADA e seguida por um numeral de 1 a 5 (total de sujeitos da pesquisa). O material coletado foi analisado segundo as experiências de desgaste à saúde mental dos sujeitos, na perspectiva da determinação social do processo saúde-doença, de acordo com o nosso objetivo de investigar o perfil epidemiológico nas vertentes de vida e de trabalho das mulheres internadas na Unida- 
de de Cuidado Intensivo da Casa de Saúde São Camilo de Léllis em Mossoró/RN. Paralelamente aos depoimentos coletados através das entrevistas, consultamos os prontuários médicos das pacientes na Unidade e, conversamos com a equipe de enfermagem a respeito das pacientes entrevistadas, para a consolidação de uma perspectiva mais geral dos sujeitos da pesquisa. Com isso, tivemos os dados dos pacientes, a versão médico-psiquiátrica e a visão da equipe de enfermagem, sobre o processo de internação e reinternação das pacientes.

\section{DESENVOLVIMENTO E DISCUSSÃO: DA VIVÊNCIA DAS MULHERES INTERNADAS NAUNIDADEDE CUIDADOS INTENSIVOS (UCI-CSSCL)}

A Unidade de Cuidados Intensivos (UCI Feminino), é parte da Casa de Saúde São Camilo de Lélis (CSSCL) e subdivide-se em setor interno (sintomatologia aguda) e setor externo (sintomatologia "estabilizada").

É uma unidade de caráter emergencial que dispõe de um total de 45,69 leitos permitidos e 43 leitos existentes, sendo 16 no setor interno e 27 no setor externo. Conforme o registro diário da unidade pudemos constatar uma média que varia de 40 a 45 pacientes internadas mensalmente, cujo diagnóstico predominante é o 295.0/5: esquizofrenia simples.

A equipe profissional dispõe de 01 (um) enfermeiro por turno (manhã e tarde), 01 (um) técnico de enfermagem, 02 (dois) auxiliares de enfermagem, que atuam cotidiana e diretamente com as pacientes. Mais periodicamente a unidade dispõe de 01 (um) psicólogo, 06 (seis) médicos psiquiatras (rotativos), 01 (um) terapeuta ocupacional, 01 (um) nutricionista, 01 (um) assistente social, 01 (um) servente, 02 (duas) copeiras.

As mulheres que chegam a UCI são provenientes do posto da CSSCL ou encaminhadas por outros serviços da localidade, conforme apresente-se o quadro psiquiátrico caracteristicamente emergencial. Como atitudes básicas nas situações de crise e de emergência mais freqüentes, destaca-se a agitação delirante e a agitação maníaca onde o paciente mostra-se gravemente ansioso, refere delírios e alucinações, euforia intensa, insônia e heteroagressividade.
Para Saraceno ${ }^{(8)}$, esses comportamentos demandam uma atitude afetiva e direta por parte dos profissionais envolvidos com vista ao controle da situação, reabilitação do paciente e satisfação do trabalhador em saúde mental. Essas atitudes geram a necessidade de um serviço psicoterapeuticamente intensivo, podendo ser de utilidade necessária o emprego de medicamentos antipsicóticos adequados a cada caso, juntamente com o suporte de outras terapêuticas, como a análise individual e/ou grupal e a terapêutica ocupacional.

A UCI Feminino da CSSCL, por ser uma unidade de um hospital psiquiátrico tradicional, possui características de uma unidade fechada, sendo comum a disposição das mulheres pelo pátio notadamente impregnadas pela medicação prescrita: umas mostram-se apáticas, enquanto outras movimentam-se e falam continuamente.

Conforme o grau de sofrimento psíquico e de impregnação medicamentosa, nem sempre é possível manter uma conversa com idéias devidamente concatenadas, mas sim, conversas aparentemente estanques/partidas, em geral marcadas por uma angústia lancinante das internadas. Consideramos importante trazer alguns trechos desses depoimentos, os quais passamos a transcrevê-los a seguir.

\section{E/1, 43 anos:O Deus que eu encontrei é o Deus da estrada, eu não quero que a mi- nha filha tenha a vida que eu tive.}

Natural de Dr. Severiano Gomes-RN, a E/1 casou-se aos 33 anos com um viúvo que tinha nove filhos. Ela teve três filhos dos quais cuidou, além dos seus enteados. Durante a entrevista apresenta crises de choro, diz que viveu "trabalhando para os outros". Refere ter exercido a profissão de doméstica. Tem nível de escolaridade correspondente ao primeiro grau menor (primeira à quarta série). O fragmento supracitado de sua fala, pode ser associado à indignação da paciente frente à sua vida, marcada por "desenganos" na esfera privada e no que tange às tarefas de trabalho, não é menor o traço de amargura, quando relata a submissão/subserviência dos afazeres de empregada doméstica. A decepção referente ao simbolismo religioso associado ao movimento e a incerteza - a estrada - denota no que se traduziu para a paciente as suas idas e vindas de instituições psiquiátricas que operam o
Considerações sobre vida e trabalho de mulheres internadas em uma unidade psiquiátrica 
Jacileide Guimarães Soraya Maria de Medeiros significado de deslocamento e exclusão da normalidade e, por extensão, da sociedade, expresso no conhecimento de uma vida que ela não quer para a sua filha.

\section{E/2, 23 anos:Eu pensava muito em minha mãe e fiquei impressionada com uma bes- teira que ela disse.}

Natural de Luiz Gomes-RN, a E/2 reclama que os pais tinham muitos conflitos. Casouse aos 20 anos. Diz que a mãe e irmãos "têm problema de nervosismo". Tentou estudar "mas não deu certo", trabalhou como doméstica. Martirizava-se com o fato de sua mãe têla chamado de prostituta. Não ficou claro em nossas pesquisas se realmente vivenciou a condição de prostituta ou se era uma forma de rótulo/discriminação verbalizada pela sua mãe, que teve grande repercussão na autoestima da paciente. Do trabalho, referia-se a "dureza" de ser empregada doméstica, por ter que cumprir o que se manda e nunca "está bom pra patroa (sic)".

\section{E/3, 29 anos:Estudei muito, adoro cinema: Julia Roberts, Michelle Pfeifer, Perdidos na Noite ... Fui gerente da Arezzo, mas tive que deixar por problemas em casa, minha família...}

Natural de Martins-RN, a E/3 "amancebouse" segundo a entrevistada, com 22 anos. Tem dois filhos. Diz ter trabalhado como gerente de loja. Refere ter estudado até o primeiro grau completo. Embora tenha alcançado um patamar de escolaridade diferenciado, com relação as demais entrevistadas e com isso uma inserção profissional também diferente, diz ter sofrido muito com a pressão da família, que acabou por "enlouquecê-la". Pudemos constatar através da entrevista e do prontuário médico, que a família da paciente era financeiramente diferenciada, porém nutria conflitos de interesse quanto aos rumos que a paciente dava a sua vida, por ter-se unido a um homem divorciado. Nestes termos, inferimos o peso da moral, que se sobressai fortemente sobre a condição da mulher, como por exemplo, cobranças quanto a virtuosidade estabelecida no que tange às regras de "bom comportamento".

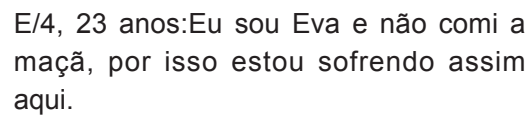

Natural de Messias Targino-RN, a E/4 foi "junta mais de dois anos"; diz ter três filhos, embora a sua mãe refira a existência de ape- nas duas crianças. Refere ter sofrido demais, mas prefere não detalhar tal sofrimento. Trabalhou como doméstica. Em seu discurso pode-se perceber um imaginário simbólico com aspectos religiosos no qual buscava justificar o seu sofrimento, fato recorrente em discursos de pacientes psiquiátricos reinternados. É interessante notar a inversão que a paciente faz, ao referir seu sofrimento por "não ter comido a maçã", quando a versão bíblica da expulsão do paraíso e advento do sofrimento humano, justifica-se ao contrário, pela desobediência de Eva que provou do fruto proibido. O sofrimento humano, canônico, parece pouco para a paciente, comparado à avaliação que ela faz da sua situação.

E/5, 37 anos:Fiquei assim doente depois que peguei o meu marido na cama com a empregada.

Natural de Almino Afonso-RN, a E/5 casou-se duas vezes. Tem duas filhas do último casamento. Perdeu a mãe e a guarda das crianças, recentemente. Trabalhou no comércio. Tem segundo grau completo. Aqui, a condição de gênero, emerge como fator marcante, quando a paciente enfatiza a traição e correlata indignação como desencadeador da doença. É interessante notar, que diferentemente das entrevistadas anteriores, cuja profissão predominante era empregada doméstica, neste caso, trata-se de uma patroa, que centraliza o decurso da doença na esfera da vida íntima. No âmbito da classe média-baixa, a moral, assume graus crescentes, que para essa paciente terminou por forçá-la a escolher entre "manter-se traída" ou enlouquecer.

A análise desse estudo busca o processo saúde-doença do sofrimento psíquico centrado nas formas de vida e de trabalho dos sujeitos entrevistados, considerando ainda que sucintamente, a abordagem de gênero enquanto diferenciação psicológica e subjetiva além da diferença biológica entre homem e mulher. Na perspectiva do ser mulher pode-se identificar uma pressão cumulativa no que tange ao modo de viver e de trabalhar, agravada pelas expectativas morais da vida em sociedade..

Sampaio ${ }^{(9)}$ refere-se à "violência biológica", a qual submete-se a mulher que além de participar ativamente da fecundação; menstrua, gesta, amamenta e sofre as conseqüências da queda das taxas hormonais 
psicossomaticamente. Some-se a este fato outras violências como as instituições onde mulheres ainda são inferiorizadas nas relações de trabalho e salário.

Para Fonseca ${ }^{(10)}$ a mulher na sociedade atual encontra-se submetida a uma "tripla jornada de trabalho", onde sofre as injunções do trabalho profissional (fora de casa), do trabalho doméstico (dentro de casa) e do trabalho reprodutivo (ocupação com os filhos e família em geral).

Oliveira ${ }^{(11)}$ refere-se, metaforicamente, à vida da mulher brasileira como legada a uma "ordem esquizofrenizante" — esquizofrenia em grego significa literalmente "mente partida" ou "mente dividida" — onde ela se divide entre um ser privado (doméstico, mantenedor) e um ser público (provedor).

Em nossa investigação pudemos constatar experiências comuns a todas as entrevistadas, salvo as peculiaridades de cada vivência: todas são multíparas, encontramse na faixa etária oscilante entre 23 e 43 anos de idade, residem na cidade de Mossoró-RN, possuem baixo grau de escolaridade que por sua vez determina a semelhança entre as suas ocupações e inserção no mundo do trabalho. Referem decepções afetivas contundentes e sofrimentos com relação à violência. Todas possuíam histórias de violência em família, como conflitos de opinião, agressão moral e até violência física, fatos sustentados pelos relatos dos prontuários médicos e enfatizados pelo desgaste da vida familiar, traduzido pelas entrevistadas, como experiências de opressão e traição. Constatamos nos momentos de entrevistas e observação de campo, por ocasião das visitas dos familiares, o sentimento de solidão das mulheres internas na UCI da CSSCL: a expectativa da espera; a frustração da ausência; a dor não dita, guardada na aparente indiferença ou agressividade, falam pelo freqüente abandono em que sobrevivem num ambiente hospitalar psiquiátrico tradicional.

As mulheres da UCI-Feminino, são em sua maioria, de classe social baixa, cujas agruras de suas formas de trabalhar são demarcadas pela submissão/expropriação e conseqüentes formas de viver marcadas pela exacerbação da ansiedade e do pânico advindos de vidas inscritas em histórias de violência laboral e, violências cotidianas, afetivas e corporais, que competem para pouca ou nenhuma auto-estima e para uma qualidade de vida denegrida por episódios constantes de agressões físicas e psicológicas.

Assim encontramos, tecido o impacto do processo saúde-doença, enquanto determinação social sobre a saúde mental, que não de forma simples, mas historicamente construído, insere-se como elemento potencializado pelas formas de vida e de trabalho dos sujeitos sociais, e, potencializador de desgaste em detrimento do benefício mental. Constatamos esse nexo causal entre o processo saúde-doença mental e as condições de vida e de trabalho das mulheres pesquisadas, onde ora a opressão da esfera privada de suas vidas, ora a pressão de suas atividades laborais, redundaram no agravamento do sofrimento psíquico, mas sempre ambas as situações se potencializaram para o desfecho da primeira internação psiquiátrica, que no caso das entrevistadas, significou subseqüentes altas e reinternações hospitalares que inscrevem o circuito da "carreira psiquiátrica" das pessoas com sofrimento psíquico.

A saúde mental, como esfera constituinte do ser social em sua totalidade/singularidade, é potencializada para o pólo saúde ou para o pólo doença, conforme a presença respectiva de benefícios ou desgastes cotidianos, o que por sua vez, recebe determinação da inserção social dos sujeitos em sociedade. Articulada ao modelo neoliberal a condição destes determinantes tende a exacerbar o desgaste e conseqüente comprometimento biopsíquico das camadas de baixa renda, como pudemos comprovar segundo o presente estudo.

\section{CONSIDERAÇÕES FINAIS}

O trabalho-vida-saúde e seu impacto na saúde mental, aqui estudado, em consonância com a produção teórica existente, denotaram uma determinação social da produção do quadro de morbidade e sofrimento psíquico.

O processo saúde-doença, contribui para a deflagração do sofrimento psíquico que subsidiado pelas políticas de saúde mental tradicionais - o caso do modelo manicomial da CSSCL — retroalimenta-se fortalecendo o risco em detrimento do benefício, considerando que todas as mulheres pesquisadas têm
Considerações sobre

vida e trabalho

de mulheres

internadas em uma

unidade psiquiátrica 
Jacileide Guimarães Soraya Maria de Medeiros reingresso na CSSCL. Este fato revela o famigerado fenômeno da "porta-giratória" nas instituições psiquiátricas que culminam na conhecida cronificação hospitalar e recíproca exclusão social da pessoa com sofrimento psíquico. Vale ressaltar que até o momento dessa pesquisa, na cidade de Mossoró-RN, as relações concernentes à assistência em psiquiatria e saúde mental são predominantemente hospitalocêntricas, onde apesar de existir um centro de referência ambulatorial para a região, o seu funcionamento tem se caracterizado pela distribuição de medicamentos e triagem dos usuários para atendimento na CSSCL, ou seja, à revelia do movimento da luta antimanicomial e da prática de reestruturação psiquiátrica no Brasil, a assistência prestada em muitos serviços de saúde mental nos mais variados espaços do território nacional, mudou de nomenclatura, mas mantém o saber/prática custodial.

\section{REFERÊNCIAS}

(1) Barata RCB. A Historicidade do conceito de causa. In: Escola Nacional de Saúde Pública. Textos de apoio: epidemiologia. 1985. p. 13-27.

(2) Queiroz VM, Salum MJL. Documentos pedagógicos. São Paulo: EE/USP. 1996. [Mimeografado.]

(3) Possas CA. Saúde e trabalho: a crise da previdência social. Rio de Janeiro: Graal; 1981.

(4) Joffily B. Toyotismo e microeletrônica: uma revolução que desafia. Rev de Fato. 1994; 1(2):14-25.

(5) Medeiros SM. A globalização da economia e a questão da democracia. Ribeirão Preto; 1997. [Mimeografado.]

(6) Antunes R. Adeus ao trabalho? ensaio sobre as metamorfoses e a centralidade do mundo do trabalho. São Paulo: Cortez, 1997.
(7) Bastos FIP, Castiel LD. Epidemiologia e saúde mental no campo científico contemporâneo: labirintos que se cruzam? In: Amarante $\mathrm{P}$, (organizador). Psiquiatria social e reforma psiquiátrica. Rio de Janeiro: Fiocruz; 1994. p. 97-112.

(8) Saraceno B, Asioli F, Tognoni G. Manual de saúde mental: guia básico para atenção primária. São Paulo: Hucitec; 1994.

(9) Sampaio JJC. Saúde mental. In: Rouquayrol MZ. Epidemiologia e saúde. Rio de Janeiro: Medsi; 1993. p. 403-420.

(10) Fonseca RMGS. Gênero: categoria analíticointerpretativa das condições de vida e saúde da coletividade. [Apresentado no $47^{\circ}$ Congresso Brasileiro de Enfermagem; 1995 nov.19-24; Goiânia].

(11) Oliveira RD. Elogio da diferença: o feminino emergente. São Paulo: Brasiliense; 1991. 